\title{
Introducing the July 2021 Issue
}

\section{Charles B. Hodges ${ }^{1}$ (D)}

Published online: 2 July 2021

(C) Association for Educational Communications \& Technology 2021

Welcome to the July 2021 issue of TechTrends! This may be the biggest issue of the journal ever published. I hope you will find it to be a nice addition to your summer reading. This is a regular issue of the journal, but it contains a special section of papers on the role of creative risk taking and productive failure in education and technology futures. The special section was edited by Danah Henriksen, Punya Mishra, Edwin Creely, and Michael Henderson. You can read more about this special section in their Guest Editors' Notes. I really appreciate their work putting this special section of the journal together!

In addition to the special section, this issue includes some of our regular columns, like ICT International, The History Corner, and Graduate Member Musings. You can read a brief update on planning for the fall 2021 AECT convention in the Conference Planning column. The issue also includes 15 original papers covering an eclectic mix of topics.

The original papers begin with a technoethical audit of Google by Daniel G. Krutka, Ryan M. Smits, and Troy A. Willhelm which addresses ethical, legal, democratic, economic, technological, and pedagogical concerns educators, students, and community members should consider. Next, a team from the UK led by Alejandro Armellini provides university students' perceptions of their learning and social experiences in the context of an institutionwide pedagogic shift to Active Blended Learning. Preservice education students and the implementation of digital identities is the topic of the next paper by Ian O'Byrne and Tracey Hunter-Donigeras where they investigated the process of helping educators create a domain of their own while they consider the role of technology and digital identities in their future classrooms. Obery,

Charles B. Hodges

chodges@georgiasouthern.edu

1 Georgia Southern University, Statesboro, GA, USA
Lux, Cornish, Grimberg, and Hartshorn are up next, with their examination of middle school students' use of formative assessment technologies in informal science learning contexts. The purpose of the next paper, by Meter, Budziszewski, Phillips, and Beckert, is to facilitate understanding of college students' current and previous experiences with cyberbullying and negative social media experiences. The purpose of the next paper, by Parrish and colleagues, is to describe the development of the Integrated Online-Team-Based Learning (IOTBL) model along with students' perceptions of IOTBL. O'Byrne, Kenney, and Wolfe describe one institution's attempts to set a baseline for technology-enhanced learning. Following O'Byrne, Kenney, and Wolfe are Giboney and colleagues with their approach to cybersecurity education and helping students develop professional understanding in the form of a Playable Case Study. In the next paper, Rafael Leonardo da Silva examinines moral decision-making processes of prospective government workers. Next, the team of Shanshan Ma, Gerald Knezek, and J. Michael Spector report on their investigation of university students' perceptions of social media as a learning resource (SM-LR) in China and the USA. Then, Nur Siyam and Malak Hussain provide an analysis of the cyber-safety policies of twenty private schools in Dubai. Following Siyam and Hussain, Torrey Trust and colleagues explore why educators are motivated to learn about new technologies, such as augmented reality (AR), virtual reality (VR) and 3D printers, what they already know about these tools, and what they want to know. Rebecca Quintana and Yuanru Tan are up next with an innovative approach to learning design representations called course composition diagrams. Community college student perceptions of remote learning shifts due to COVID-19 are reported next by Christopher Prokes and Jacqueline Housel. The final regular paper in the issue, by Francom, Lee, and Pinkney, report on their survey study of the technologies and strategies k-12 teachers used during their experience with emergency remote education in response to the COVID-19 pandemic. I hope 
you have no trouble finding something in this issue to read with great interest.

As always, if you are interested in submitting a manuscript to TechTrends, or if you want to be a reviewer, please contact me. Encourage your colleagues to submit their work to TechTrends, to read TechTrends, and to consider joining AECT! If you have a question about the journal, my phone number is $912-478-0497$ and my email address is chodges@georgiasouthern.edu. Email is the best way to reach me. Also, you can follow TechTrends on Twitter: @ AECTTechTrends.

Publisher's Note Springer Nature remains neutral with regard to jurisdictional claims in published maps and institutional affiliations. 